\title{
Square reinforced CFST column to RC beam joint subjected to lateral loading: An investigation using finite element analysis
}

\author{
Zheng Zhou ${ }^{\text {a }}$, Dan Gan**, Xuhong Zhou ${ }^{\text {a }}$, Kang Hai Tan ${ }^{\mathrm{b}}$ \\ ${ }^{a}$ Key Laboratory of New Technology for Construction of Cities in Mountain Area (Chongqing University), \\ Ministry of Education, Chongqing 400045, China \\ ${ }^{\mathrm{b}}$ School of Civil and Environmental Engineering, Nanyang Technological University, Singapore 639798, \\ Singapore \\ * corresponding Author. E-mail address: gandan@cqu.edu.cn (Dan Gan)
}

\begin{abstract}
Concrete-filled steel tube (CFST) columns have been applied popularly in recent years, where they were connected with reinforced concrete (RC) beams or steel beams in a building. This paper proposes a joint system which connects the square reinforced concretefilled thin-walled steel tube (RCFTWST) column and RC beam. In the joint system, reinforced bars are located in the square CFTWST column, and stiffeners are welded at adjacent sides of the square steel tube. Besides, the panel zone is strengthened by internal diaphragms. A finite element model (FEM) based on software ABAQUS was developed to evaluate the behavior of the proposed joint system under lateral loading, and parametric analysis was carried out. Based on the analysis results obtained from FEM, some important parameters were chosen. And two specimens were tested under combined axial compression and low-cyclic lateral load to assess the seismic performance of the proposed joint system. The axial load level was chosen as the parameter. Test results showed that all tested specimens performed well up to $5 \%$ drift and can satisfy the seismic requirements of "strong-joint weak-component". In addition, the finite element model (FEM) is verified by comparing with the experimental results. The results can be well predicted by the model.
\end{abstract}

Keywords: square reinforced concrete-filled thin-walled steel tube (RCFTWST), finite element model, parametric analysis, seismic performance.

\section{Introduction}

Concrete-filled steel tube (CFST) columns possess distinctive advantages over conventional $\mathrm{RC}$ and steel columns and have gained increasing applications in high-rise buildings. Square CFST columns provide prominent architectural functions, regular indoor space, and larger moment resistance when compared with circular CFST columns. They are extensively used as structural members due to high efficiency.

The use of thin-walled steel plates and tubes is attractive due to ease of weld and economic advantages. Therefore, the demand for concretefilled thin-walled steel tube (CFTWST) column is increasing. However, thin-walled steel tubes are more susceptible to local buckling [1-2]. To delay local buckling of square steel tubes and to enhance confinement effect to the infilled concrete, one type of square CFST column with stiffeners welding at adjacent sides of the steel tube was proposed by Gan et al. [3], as illustrated in Fig.1, and composite effect of the columns is significantly improved.

Beam-column connections are the most critical components of a frame structure. CFST column-steel beam and CFST column-RC beam connections are generally used in CFST structures. As for CFST column-steel beam joints, joint systems with internal and external diaphragms are widely used [4-5], where the diaphragms mainly transfer the forces from flanges induced by beam bending moment. CFST column-RC beam joints are mainly used in China due to cost advantages. A safe, reliable and convenient CFST column-RC beam joint is always a challenge for steel-concrete composite construction. Nie et al. [6], Tang et al. [7], Zhang et al. [8], Pan et al. [9] and Liao et al. [10] experimentally investigated the monotonic and 
seismic behavior of square CFST-RC beam joints, and concluded that the proposed connection showed good structural performance. However, site welding or complex reinforcement detailing in the joint region is inevitable.

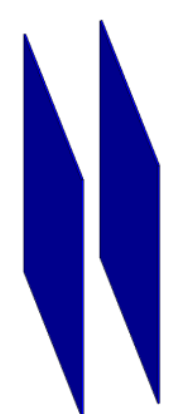

(a) Sheet metal

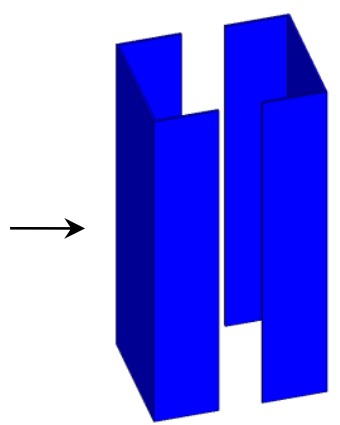

(b) U-shaped coldformed section

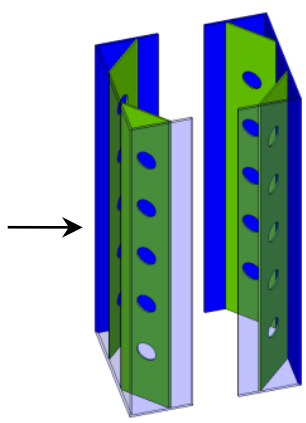

(c) Welding stiffeners
The internal diaphragms used in CFST column-steel beam joints inspired the authors to propose a novel CFST column-RC beam joint system. The proposed joint system in this study showed excellent structural performance.

Triangle confinement

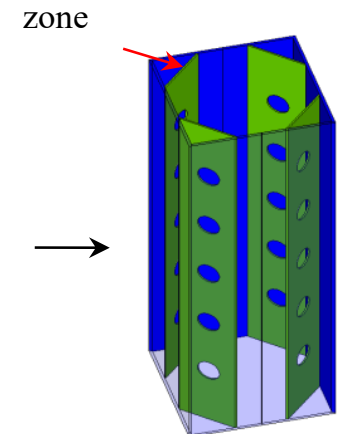

(d) Welding together

Fig. 1. Fabrication process of square tubes with stiffeners

\section{Proposed joint system}

As depicted in Fig. 2, the beam longitudinal reinforcing bars can pass through the column through the holes on the steel tube, and therefore the moment transfer can be achieved. According to [11], shear transfer capacity of the interfaces of composite section can be guaranteed. The joint panel zone is strengthened by internal diaphragms. Large-diameter steel bars are used as column longitudinal rebars and located in the triangle confinement zone (Fig. 1 (d)). The column longitudinal rebars can be fixed by the four holes at the four corners of the internal diaphragms, and thus the possibility of column bars buckling is reduced although there are no stirrups in the column. By embedding reinforcements and stiffeners in the infilled concrete, fire resistance is superior [12]. To achieve strong joint, to avoid excessive welding in the joint zone, and to keep load-carrying capacity of the column continuous. Thus, the steel tube in the joint zone is respectively extended upward and downward to half width of the tube, as shown in Fig. 2(b).

In this paper, a finite element model (FEM) based on software ABAQUS was developed to evaluate the effects of different parameters on the behavior of the proposed joint system. Parametric analysis was carried out. Based on the analysis results obtained from FEM, two specimens were tested under combined axial compression and low-cyclic lateral load to assess the seismic performance of the composite joint.
The axial load level was chosen as the parameter. In addition, the finite element model (FEM) predictions were compared with experimental results.

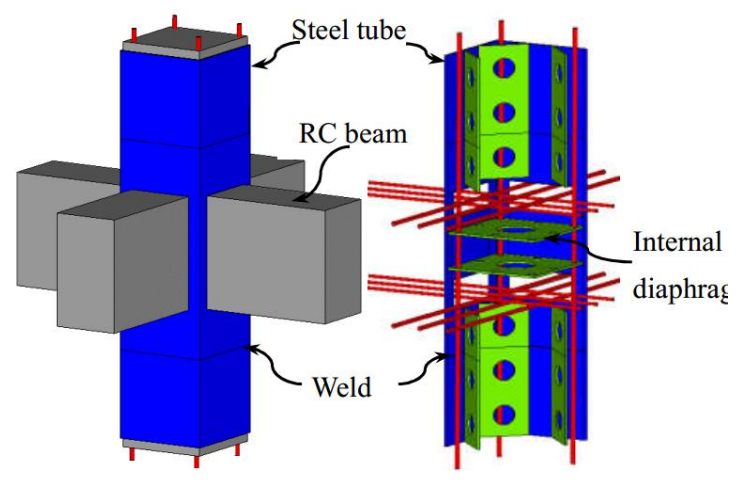

(a) CFST joint

(b) Joint and column details

Fig. 2. New joint system

\section{Numerical modeling}

\subsection{FEM numerical model and Material properties}

In the model, beams have $200 \times 350 \mathrm{~mm}$ rectangular cross-section and $1500 \mathrm{~mm}$ in length. Columns have square cross-section with dimensions of $300 \mathrm{~mm}$. Arrangement of rebars and stiffeners are shown in Fig. 4. The thickness of all steel tubes and stiffeners is $2 \mathrm{~mm}$. The yield strength of all the rebars is $400 \mathrm{MPa}$. The cylinder compressive strength of concrete used for all specimens is $40 \mathrm{MPa}$. Steel plates are grade Q235 with yield strength of $235 \mathrm{MPa}$. Modulus of elasticity and Poisson's ratio for 
steel and concrete are considered as $200 \mathrm{GPa}$ and 0.3 , and $29.7 \mathrm{GPa}$ and 0.2 , respectively.

Shell element S4R and solid element C3D8R were used to model steel tubes and concrete, respectively. Truss element T3D2 was applied for steel bars. A damaged plasticity model was used to model the concrete material. The compressive stress-strain relationships recommended by Han et al. [13] and GB2050010-2010 [14] were adopted for column confined concrete and beam unconfined concrete. For concrete under tension, the constitutive relationship model was obtained by defining the tensile stress and tensile fracture energy presented in CEB-FIP MC90 [15]. The elastic-perfectly plastic stress-strain relationship model was employed for rebars and steel tubes. A surface-to-surface contact interaction was applied at the interface of the steel tube and concrete column, by specifying a hard contact in the direction normal to the interface plane and using Mohr-Coulomb friction model with a fiction coefficient of 0.6 for the tangential behavior. Rebars, stiffeners, and internal diaphragms were embedded in the concrete.

\subsection{Loading and boundary conditions}

The connections were loaded under combined lateral force and constant axial force on the column top. A lateral force was applied to the specimen step by step until failure occurred in one direction. Constant axial load was applied to the columns in FEM. The axial load level $n_{\mathrm{o}}$ of the composite column was chosen as 0.3 . It is defined as follows:

$n_{\mathrm{o}}=\frac{N_{0}}{f_{c} A_{c}+f_{y} A_{s}}$

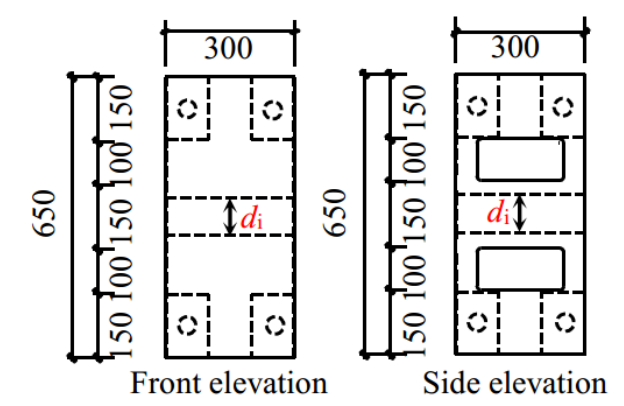

(a) Joint details in which $N_{0}$ is the axial load applied at the column top; $f_{\mathrm{c}}$ is the concrete cylinder compressive strength; $f_{\mathrm{y}}$ is the steel yield strength; $A_{\mathrm{c}}$ is the cross-sectional area of concrete; $A_{\mathrm{s}}$ is the total cross-sectional area of the steel tube and internal vertical stiffeners.

The column was supported by a pinned connection at its base but free to move laterally at the top on top. Roller supported was modeled to end of beams. The boundary conditions of specimens are shown in Fig. 3.

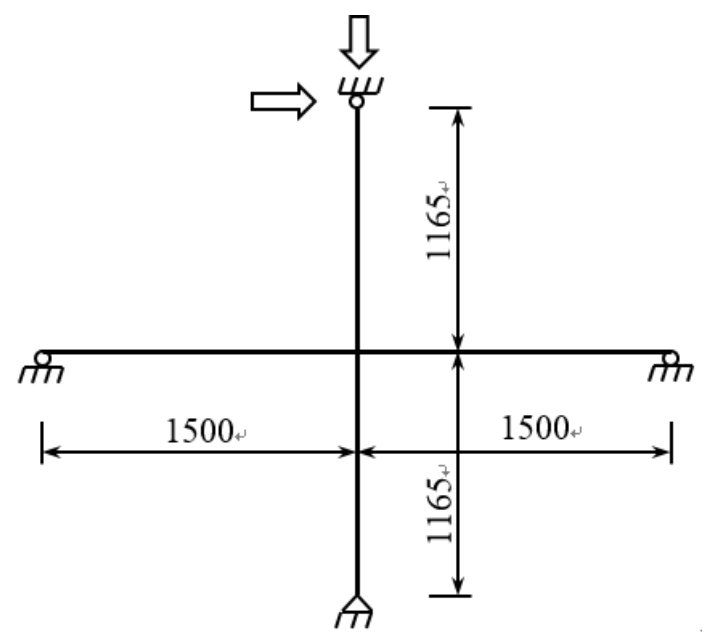

Fig. 3. Boundary condition and loading of specimens

\subsection{Parametric studies}

The key point of the proposed joint details is the arrangement of internal diaphragms. In this section, to find out the appropriate parameters, parametric studies were performed to predict the behavior of composite joints by varying critical parameters. These discussed parameters included the quantity of internal diaphragms $n$, the thickness of internal diaphragms $t_{\mathrm{d}}$, the diameter of concreting hole in internal diaphragms $d_{\mathrm{c}}$, and internal diaphragms interval $d_{\mathrm{i}}$, as shown in Fig. 4.
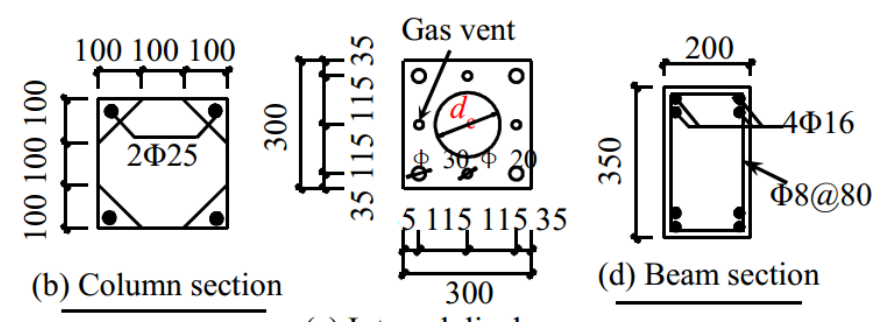

(c) Internal diaphragm

Fig. 4. Details of the composite joint 
(1) Quantity of internal diaphragm $n$ (Fig. 5)

The quantity of the internal diaphragms would influence the confinement effect of the joint tube. Besides, the greater the number of internal diaphragms were, the less convenient the concrete casting could be. The quantities of internal diaphragms were set to $0,1,2$ and 3 in the study.

The ultimate strength of the composite joint increased with increasing number of internal diaphragm $n$. This is attributed to the fact that failure mode varied from joint shear failure $(n=0)$ to beam flexural failure $(n \geq 1)$, which indicates that the existence of internal diaphragms could change the failure modesfrom jont shear failure to beam flexural failure. However, the ultimate strengths had little difference when the number of internal diaphragms $n$ lager than 1, because the beam flexural failure dominated the strength and the ultimate strength was hardly affected in this range.

(2) Thickness of internal diaphragm $t_{d}$ (Fig. 6)

The thickness of internal diaphragms can affect the tensile force and change the confinement of the joint tube to core concrete. The ultimate strength of the composite joint increased with thicker internal diaphragms, and
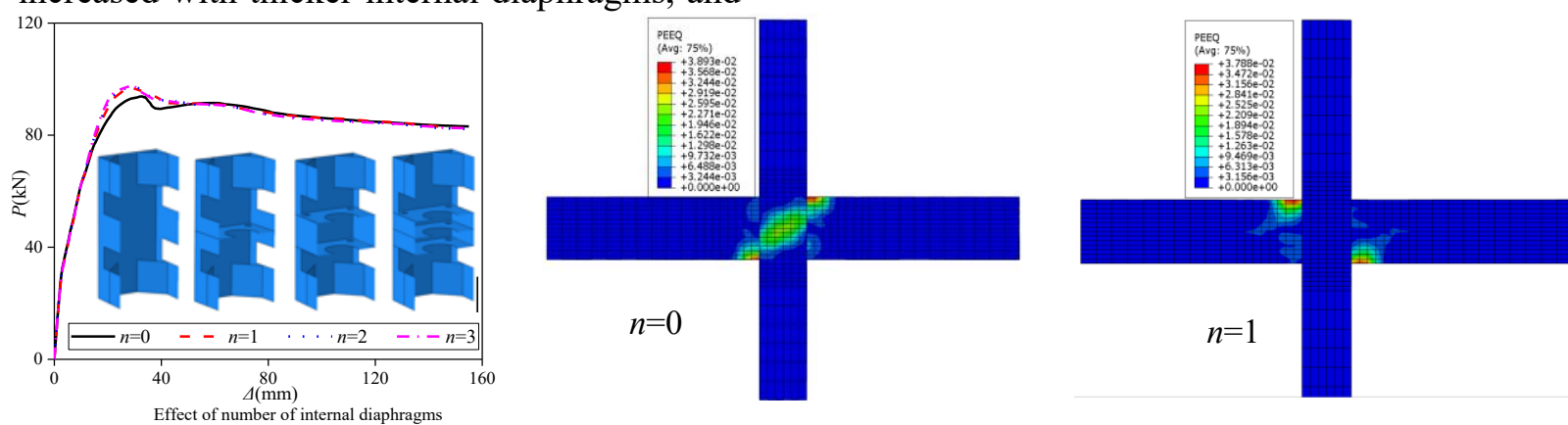

Fig. 5. Effect of $n$

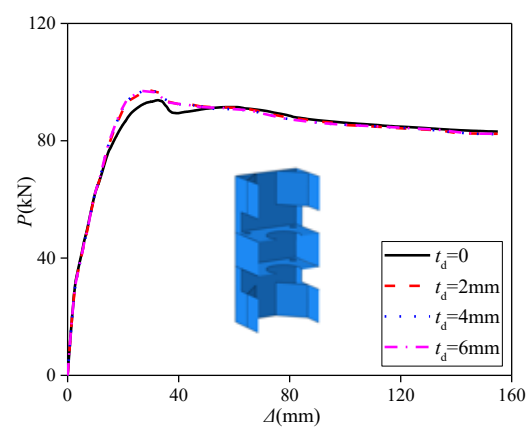

Fig. 6. Effect of $t_{\mathrm{d}}$ therefore the failure mode changed from joint shear failure $\left(t_{\mathrm{d}}=0 \mathrm{~mm}\right)$ to beam flexural failure $\left(t_{\mathrm{d}} \geq 2 \mathrm{~mm}\right)$.

(3) Diameter of concreting hole in internal diaphragm $d_{\mathrm{c}}$ (Figs. 7)

With increasing diameter of concreting hole, concreting will be easier, but the effective area of the internal diaphragms will be less leading to a decreased load-carrying capacity. Fig. 7 shows a comparison of the calculated results for different concreting hole of an internal diaphragm. Both the strength and stiffness of the joint were not significantly influenced by this parameter. Consequently, the concreting hole can be larger to ensure better concreting quality.

(4) Interval of internal diaphragm $d_{\mathrm{i}}$ (Fig. 8)

The ultimate strength of the specimen increased with decreasing $d_{\mathrm{i}}(350 \mathrm{~mm}-150 \mathrm{~mm})$, while the specimen showed almost the same behavior with further decrease of $d_{\mathrm{i}}(150 \mathrm{~mm}$ $0 \mathrm{~mm})$. The specimen with $d_{\mathrm{i}}$ of $350 \mathrm{~mm}$, where the internal diaphragms located just above and below the longitudinal beam bars, suffered joint shear failure. As a result, to obtain a better behavior, the internal diaphragms should be located between the two holes where the longitudinal beam bars pass through.

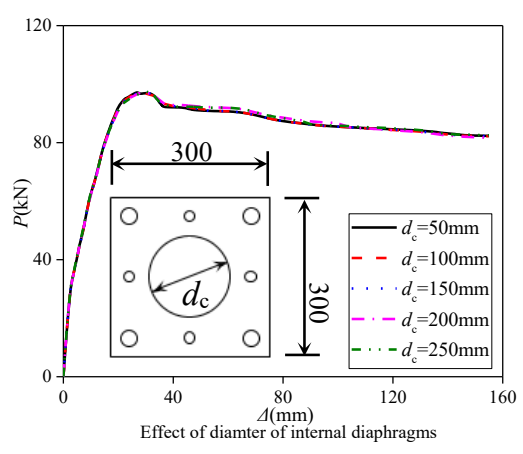

Fig. 7. Effect of $d_{\mathrm{c}}$

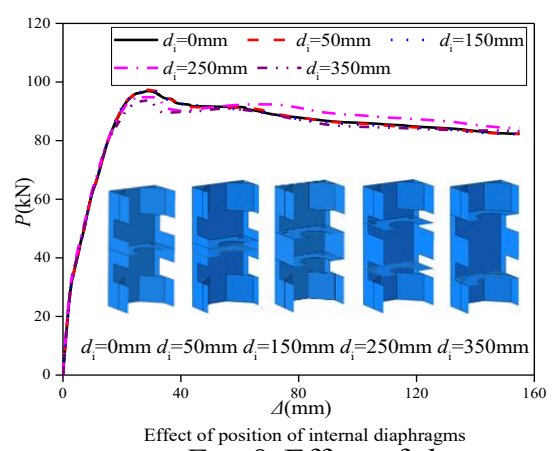

Fig. 8 . Effect of $d_{\mathrm{i}}$ 


\section{Experimental study}

\subsection{Specimen details}

To assess whether the proposed composite joint could satisfy the seismic requirements of "strong-joint weak-component" and evaluate the validity of mentioned FEM methods, two RCFTWST column to RC beam joints, namely CJ-1, CJ-2, were tested. According to the results obtained from parametric studies, the following parameters were chosen: $n=2, t_{\mathrm{d}}=4 \mathrm{~mm}$, $d_{\mathrm{c}}=150 \mathrm{~mm}$, and $d_{\mathrm{i}}=150 \mathrm{~mm}$. The axial load level was chosen as the parameter. Details of the composite columns are shown in Table 1, where $D$ and $t_{\mathrm{t}}$ are the width and thickness of the column tube, respectively; $t_{\mathrm{s}}, t_{\mathrm{j}}$ and $t_{\mathrm{d}}$ are the thickness of the stiffener, joint tube and internal diaphragm, respectively; the column moments $\left(\sum M_{\mathrm{c}}\right)$ and the beam moments $\left(\sum M_{\mathrm{b}}\right)$ were calculated by finite element analysis using the tested material properties; the axial load level $n_{\mathrm{o}}$ of the composite column was chosen as 0.23 and 0.46 .

The dimensions, reinforcement and some other parameters are the same as those used in the FEM. The measured steel properties of the specimens are listed in Table 2. The beam reinforcement of two specimens was specified in the parametric studies as grade 400 bars $\left(\Phi 16, f_{\mathrm{y}}\right.$ $=400 \mathrm{MPa}$ ). It was found on delivery of the reinforcement that the $16 \mathrm{~mm}$ bars were highstrength reinforcement $\left(f_{\mathrm{y}}=607.5 \mathrm{MPa}\right)$. It was decided to proceed with construction because the calculated ratio of the column moments $\left(\sum M_{\mathrm{c}}\right)$ to the beam moments $\left(\sum M_{\mathrm{b}}\right)$ did not affect the strong-column weak-beam design of the test units. The same concrete mix was used to fabricate all composite columns and RC beams, and the cylinder compressive strength was 37.2 MPa.

The test setup is shown in Fig. 9. The loading procedure consisting of displacement-controlled steps is illustrated in Fig. 10.

Table 1. Summary of specimen information

\begin{tabular}{ccccccccc}
\hline Specimens & $D \times t_{t}(\mathrm{~mm})$ & $t_{s}(\mathrm{~mm})$ & $t_{\mathrm{j}}(\mathrm{mm})$ & $D / t_{\mathrm{j}}$ & $t_{\mathrm{d}}(\mathrm{mm})$ & $\sum M_{\mathrm{c}} / \sum M_{\mathrm{b}}$ & $N_{0}(\mathrm{kN})$ & $n_{\mathrm{o}}$ \\
\hline $\mathrm{CJ}-1$ & $300 \times 2$ & 2 & 2 & 150 & 4 & 2.55 & 1000 & 0.23 \\
$\mathrm{CJ}-2$ & $300 \times 2$ & 2 & 2 & 150 & 4 & 2.64 & 2000 & 0.46 \\
\hline
\end{tabular}

Table 2. Properties of steel

\begin{tabular}{cccc}
\hline Type & $\begin{array}{c}\text { Yield strength } f_{\mathrm{y}} \\
(\mathrm{MPa})\end{array}$ & $\begin{array}{c}\text { Ultimate strength } f_{\mathrm{u}} \\
(\mathrm{MPa})\end{array}$ & $\begin{array}{c}\text { Modulus of elasticity } E_{\mathrm{s}} \\
\left(\times 10^{2} \mathrm{GPa}\right)\end{array}$ \\
\hline 8 mm deformed steel bar & 410.3 & 636.5 & 2.05 \\
$16 \mathrm{~mm}$ deformed steel bar & 607.5 & 727.1 & 1.83 \\
$25 \mathrm{~mm}$ deformed steel bar & 477.5 & 592.3 & 2.10 \\
$2 \mathrm{~mm}$ thick steel plate & 302.2 & 456.3 & 2.12 \\
$4 \mathrm{~mm}$ thick steel plate & 309.2 & 452.1 & 1.94 \\
\hline
\end{tabular}




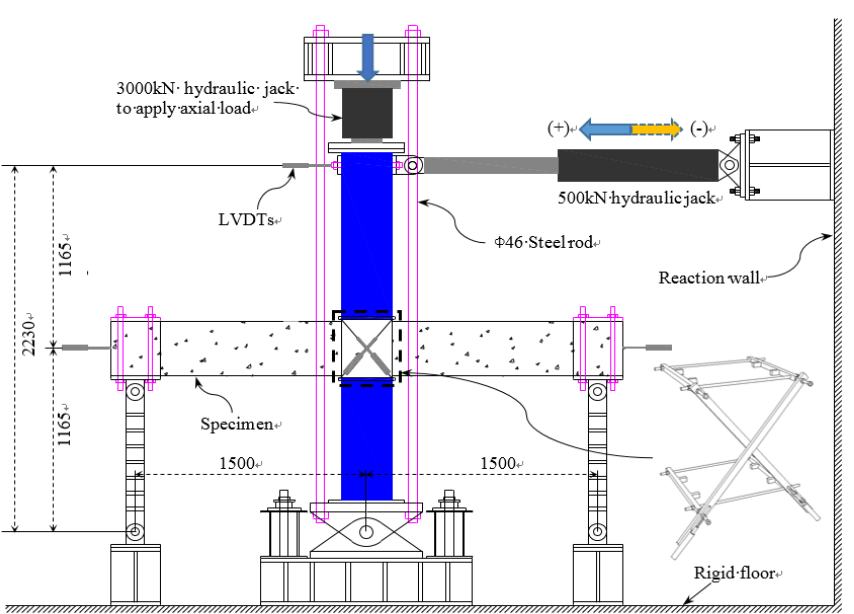

Fig. 9. Test setup

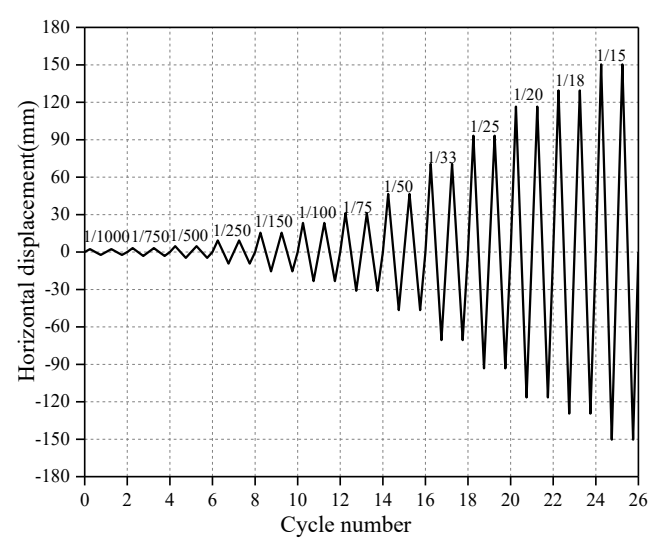

Fig. 10. Loading procedure

\subsection{Experimental results}

Specimen CJ-1 initially showed beam flexural failure, and bond failure occurred in the first cycle at 5\% drift. Specimen CJ-2 exhibited beam failure. Fig. 11 shows the crack patterns of the two failure modes at the end
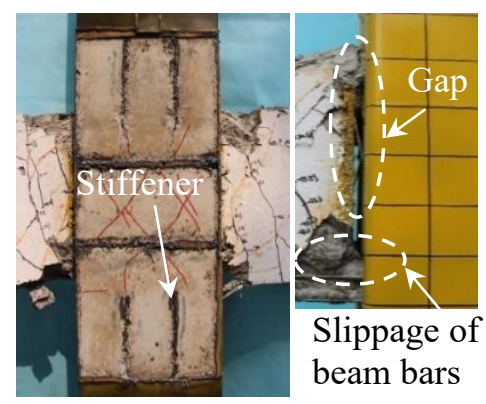

(a) Beam flexural failure with bond failure(CJ-1)

Fig. 11. Crack pattern of the test after removing the steel tube in the panel zone. Fig. 12 gives the load-column displacement hysteresis curves. Due to the page limitation of this conference paper, more information about the experimental test will be provided in another paper.

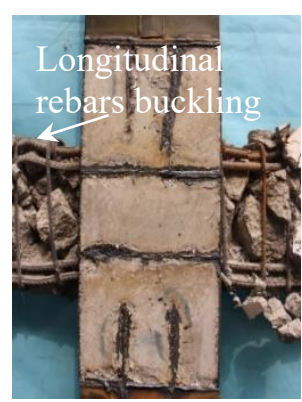

(b) Beam failure(CJ-2)

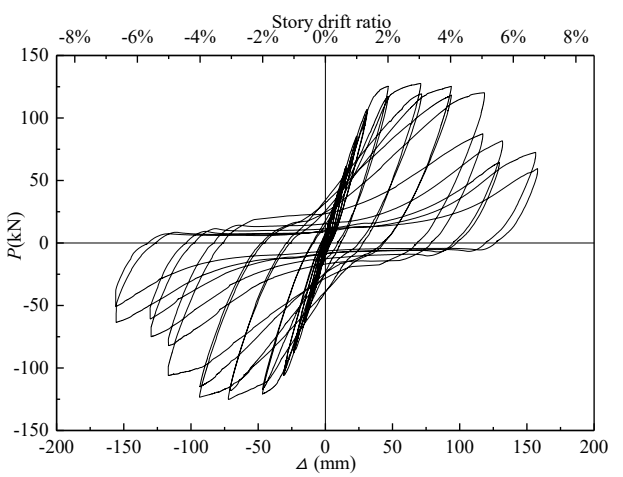

(a) CJ-1

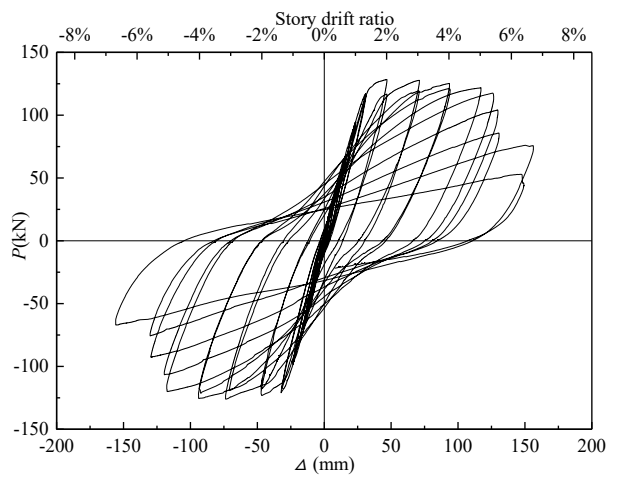

(b) $\mathrm{CJ}-2$

\section{Verification of modeling}

The FEM method mentioned in Section 3 was used to model the composite joints with the tested material properties. Fig. 13 shows the plastic strain distribution for specimen CJ-2, from which it can be seen that large plastic strains mainly concentrated at the beam end. The plastic strains in the connection region were small, which indicates that the connection zone has sufficient load-carrying capacity. This is consistent with the failure mode from the experimental results. 


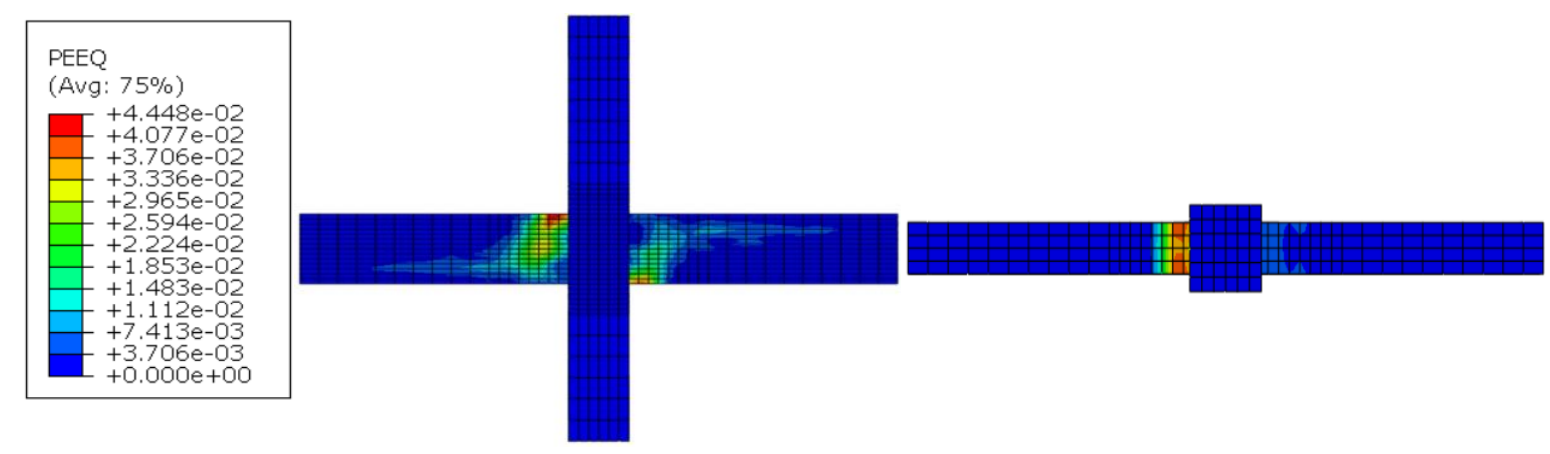

Fig. 13. Plastic strain distribution for specimen CJ-2

Comparisons of the load-displacement skeleton curves from the numerical model and from the experiments are shown in Fig. 14. It can be seen that the numerical results were in good agreement with the experimental ones before the displacement of $116.5 \mathrm{~mm}$ (corresponding to $5 \%$ drift). After that, specimen CJ-1 failed in bond failure while CJ-2 showed buckling of the beam

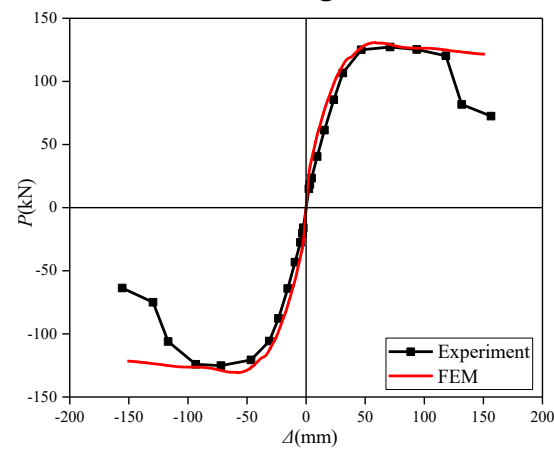

(a) $\mathrm{CJST}^{\mathrm{CE}-2-4 \mathrm{~A}}$ rebars. Thus, the lateral load descended abruptly. The FEM cannot capture these two features after $5 \%$ drift. However, the predictions compared well with the test resultsbefore 5\% drift, and this model can be considered acceptable. Therefore, the influences of different parameters were similar to those described in Section 3.3.

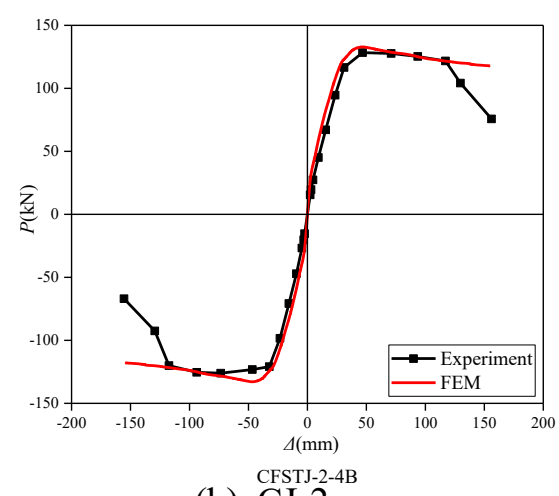

(b) $\mathrm{CJ}-2$

Fig. 14. Comparisons of load-displacement skeleton curves of FEM and experiments

\section{Conclusions}

(1) A novel composite joint system with internal diaphragms is proposed to connect square reinforced concrete-filled thin-walled steel tube (RCFTWST) column and RC beam;

(2) A FEM was developed based on finite element software ABAQUS, and further parametric studies were conducted. The specimen showed joint shear failure when there was no internal diaphragm between the two holes where the longitudinal beam bars passed through. Increasing the quantity or thickness of internal diaphragms, or decreasing the interval of internal diaphragms can enhance the ultimate strength of the joint specimen, and thus the failure mode would change from joint shear failure to beam flexural failure. While the initial stiffness of joint specimens was hardly changed by these parameters, once the beam flexural failure mode is dominated, the ultimate strength was hardly influenced;

(3) Two composite joints designed based on the parametric studies, were tested. Two failure modes, namely, beam flexural failure, and beam flexural failure with bond failure were observed in the current test. The joint specimens tested in this paper showed excellent seismic performance, and all failures occurred at large drift, and can be expected to be adopted in structures;

(4) The experimental results can be well predicted by the model before $5 \%$ drift. In order to obtain an improved behavior, at least one internal diaphragm placed at the middle-height of joint region was needed. It seemd that if two internal diaphragm were adopted, they should be place at or close to the trisecting points between the top and the bottom layers of rebars. The diameter of concreting hole should be large enough for 
concreting if the integrity of joint zone was guranteed.

\section{Acknowledgement}

The authors greatly appreciate the financial supports provided by the National Natural Science Foundation of China (nos 51378068 \& 51438001), Chongqing Research Program of Basic Research and Frontier Technology (no. cstc2016jcyjA0284) and China Scholarship Council. The opinions expressed in this paper are solely of the authors, however.

\section{References}

[1] Uy B. Strength of concrete filled steel box columns incorporating local buckling. Journal of Structural Engineering ASCE 2000; 126(3):34152.

[2] Tao Z, Han LH, Wang ZB. Experimental behavior of stiffened concrete-filled thin-walled hollow steel structural (HSS) stub columns. Journal of Constructional Steel Research 2005; 61 (7): 962-983.

[3] Gan D, Zhou Z, Zhou XH, Li J. Finite element analysis on the axial loading behavior of stub columns of square concrete-filled steel tube with diagonal ribs. Journal of Building Structures 2017, S (1): 210-217. (in Chinese)

[4] Liu XG, Tao MX, Fan JS, Hajjar JF. Comparative study of design procedures for CFST-to-steel girder panel zone shear strength. Journal of Constructional Steel Research 2014; 94 (94): 114-121.

[5] Nishiyama I, Fujimoto T, Fukumoto T, Yoshioka K. Inelastic Force-deformation response of joint shear panels in beam-column moment connections to concrete-filled tubes. Journal of Structural Engineering ASCE 2004, 130(2): 244-252.

[6] Nie JG, Bai Y and Cai CS. New connection system for confined concrete columns and beams. I: experimental study. Journal of Structural Engineering ASCE 2008; 134(12): 1787-1799.

[7] Tang XL, Cai J, Chen QJ, Liu X, He A. Seismic behaviour of through-beam connection between square CFST columns and RC beams. Journal of Constructional Steel Research 2016; 122: 151166.

[8] Zhang YF, Zhao JH, Cai CS. Seismic behavior of ring beam joints between concrete-filled twin steel tubes columns and reinforced concrete beams. Engineering Structures 2012; 39: 1-10.

[9] Pan P, Lin X, Lam A, Chen H, Ye L. Monotonic loading tests of ring-beam connections for steel reinforced concrete columns and RC beams. Journal of Structural Engineering ASCE 2014; 140 (4):04013092.

[10] Liao FY, Han LH, Tao Z. Behaviour of composite joints with concrete encased CFST columns under cyclic loading: experiments. Engineering Structures 2014; 59: 745-764.

[11] Gan D, Zhou Z, Yan F, Zhou XH. Shear transfer capacity of composite sections in steel tubed-reinforced concrete frames. Structures 2017; 12: 54-63.

[12] Romero ML, Moliner V, Espinos A, Ibañez C, Hospitaler A. Fire behavior of axially loaded slender high strength concrete-filled tubular columns. Journal of Constructional Steel Research 2011; 67(12):1953-1965.

[13] Han LH, Yao GH, Tao Z. Performance of concrete-filled thin-walled steel tubes under pure torsion. Thin-Walled Structures 2007; 45 (1): 2436.

[14] GB50011-2010. Code for Seismic Design of Buildings. Beijing, China, 2010.

[15] CEB-FIP model code 1990. Lausanne: Mai, 1993. 